\title{
POST-TRAUMATIC SYRINGOMYELIA (CYSTIC MYELOPATHY)
}

\author{
By E. R. Griffiths, O.B.E., F.R.C.S.(Edin.), F.R.A.C.S. and C. C. McCormick, \\ F.R.C.R., M.R.A.C.R. \\ Royal Perth (Rehabilitation) Hospital, Shenton Park, Western Australia 6008
}

\begin{abstract}
With careful long-term follow up of patients presenting with paraplegia at the thoraco-lumbar level it will be noted that a small group of patients emerge, constituting between one and two per cent, who will subsequently develop neurological defects at a higher level in the spinal cord. The development of cystic cavitation within the spinal cord above the level of the injury, i.e. post-traumatic syringomyelia is noted. Careful examination of the upper limbs in follow up management and investigation by metrizamide myelography is described.
\end{abstract}

Key words: Paraplegia; Syrinx formation; Upper limb involvement.

\section{Introduction}

IN any Spinal Unit which cares for large numbers of patients with traumatic spinal paralysis, there will emerge a small group of patients usually with initial injury at the thoraco-lumbar junction, or below, who subsequently develop neurological defects at a higher level in the spinal cord.

Many of these patients exhibit signs in the upper limbs similar to those seen in patients with classical idiopathic or communicating syringomyelia. In the vast majority of these patients with spinal injury, the pathogenesis of this additional defect has been demonstrated to be the formation of cystic cavities within the spinal cord above the level of injury, i.e. post-traumatic syringomyelia (cystic myelopathy) (Fig. I), (Barnett, I976).

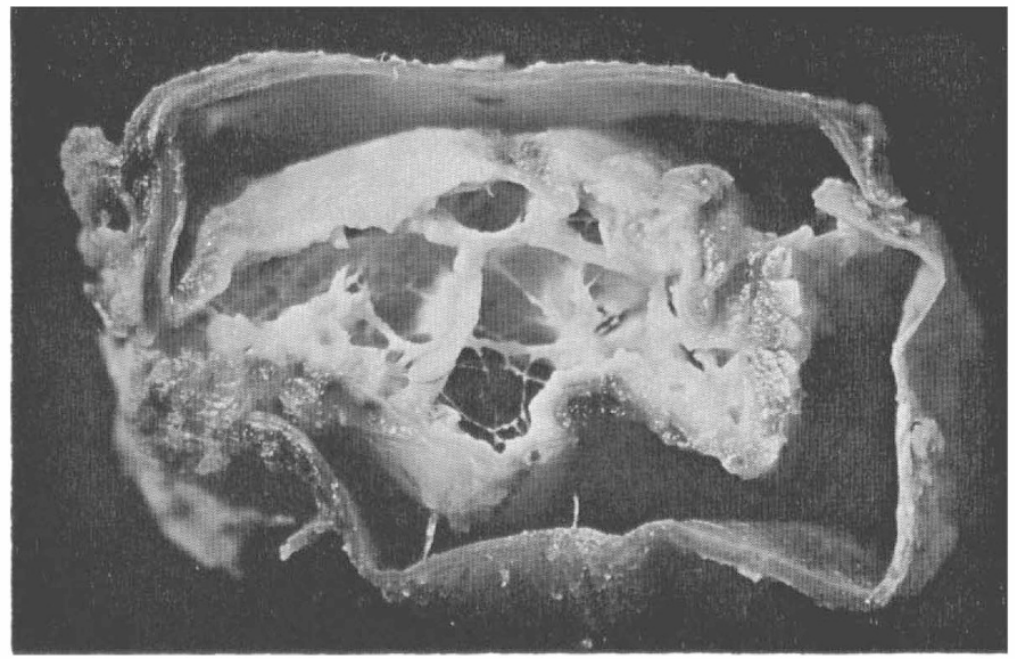

FIG. I

Spinal cord with gross cystic degeneration. 
The incidence of this complication as reported in a number of Units is shown in Table I. The incidence of this complication with initial paraplegia at the thoraco-lumbar level or below, is very much higher $(9: I)$ than in initial quadriplegics $(I: I)$. However, there does not seem to be any significant difference in incidence when patients who are initially complete or incomplete are compared. This presentation is mainly concerned with the radiographic studies which have been performed in five out of the six patients who have developed this complication in our Unit. The investigations which may be performed in this condition are shown in Table II. (Operative intra-cystic contrast studies have not been performed at this Unit.)

The spinal abnormalities commonly encountered in patients with communicating syringomyelia such as cranio-vertebral junction and cervical spine anomalies, and a widened interpedicular distance, have not been found in the post-traumatic syndrome.

\section{TABLE I}

Post-Traumatic Syringomyelia: Incidence (Barnett, I976)

\begin{tabular}{|c|c|c|c|c|}
\hline \multicolumn{3}{|c|}{79 cases recorded in the literature } & & \multirow[b]{2}{*}{$2 \cdot 03 \%$} \\
\hline Barnett & (1976) & Toronto & I9/934 Para. & \\
\hline Watson & (I972) & Sheffield & I I/IOOO Para. \& Quad. & $\mathrm{I} \cdot \mathrm{I} \%$ \\
\hline Scher & (1976) & Cape Town & 6/460 Para. & $\mathrm{I} \cdot 3 \%$ \\
\hline McCormick & (1979) & Perth & 6/325 Para. & $\mathrm{I} \cdot 8 \%$ \\
\hline \multicolumn{5}{|c|}{ Ratio-Paraplegia : Quadriplegia $=9:$ I } \\
\hline
\end{tabular}

TABLE II

Post-Traumatic Syringomyelia: Radiographic Studies

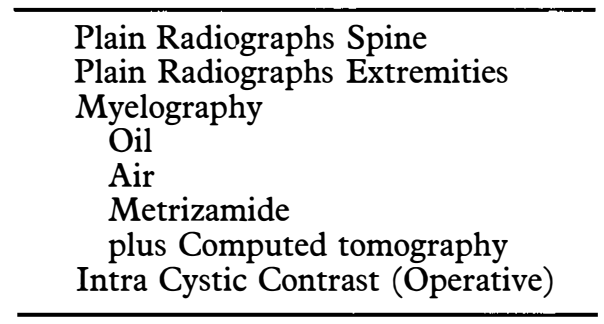

\section{Materials and Methods}

The case histories of 325 patients presenting with post-traumatic paraplegia were studied and six cases presented neurological defect in the upper limbs, three of these patients developed neuropathic joints in the upper limb with typical radiographic appearances of well-defined destruction of the bone ends, absence of osteoporosis and ossification and swelling of the peri-articular soft tissues, such as is seen in Charcot joints. These patients refused myelography.

\section{Contrast Studies of the Spine (Myelography)}

Myelography with oily contrast media, air, and more recently, metrizamide, have been widely utilised in the confirmation of the clinical diagnosis of post-traumatic 
syringomyelia. The main role of myelography in this clinical context is in the demonstration of the site of cord swelling and of the presence of fixation of the spinal cord at, or just above, the site of original injury, usually at the thoracolumbar junction (Table III). In rare cases, myelography has demonstrated causes other than post-traumatic cystic myelopathy as the cause of the patient's symptoms.

Barnett (1976) cites one patient in whom arachnoid cysts were shown, and Gardner has reported a patient in whom the typical findings of communicating syringomyelia with a Chiari malformation, and cerebellar tonsillar herniation, were found at operation. It is not generally recognised that the unequivocal confirmation of cord swelling may be quite difficult at myelography. Absolute measurement of the spinal cord diameters is obviously liable to error due to varying magnification associated with different focus/film distances (Table IV). This has been partly overcome by utilising the cord : subarachnoid space ratio in the coronal plane. It is generally accepted that if the lateral diameter of the spinal cord exceeds 80 per cent of the lateral diameter of the contrast-filled subarachnoid space, in a frontal radiograph, that the cord is expanded. The measurements must be taken at mid-body level to exclude the possibility of spurious cord swelling due to osteophytic bars at the disc levels. Examination of the lateral radiographs usually precludes this difficulty though problems may arise in those patients with a congenitally narrow spinal canal.

The combination of metrizamide myelography via cervical puncture, with CT scanning of the spinal canal, has introduced a new dimension to the radiological examination of the spinal cord. The display of the spinal cord and subarachnoid space in transverse section at computed tomography enables more accurate measurement of absolute cord size in any diameter to be made. This combination of myelography with metrizamide followed by computerised tomography of the relevant segments of the spinal canal seems to be the most appropriate radiological investigation which can be performed in the assessment of these patients.

Table V demonstrates measurements of the spinal cord in coronal and sagittal planes at the $\mathrm{C}_{2}-3$ level performed in six normal patients. The small numbers do

TABLE III

Post-Traumatic Syringomyelia: Role of Myelography

\begin{tabular}{ll}
\hline Demonstrates sites of cord cysts \\
Demonstrates cord fixation \\
Confirms & Diagnosis? \\
& Exclusion of other lesions \\
& Arachnoid cysts \\
& Chiari malformation \\
\hline
\end{tabular}

TABLE IV

Post-Traumatic Syringomyelia: Cord Measurements

Absolute measurement liable to error due to varying magnification

Cord: Subarachnoid space ratio

(Coronal)

(80\% Path.)

C.T.: Absolute measurements more accurate

(Normal range)

$19 / 2-C$ 


\section{TABLE V}

'Absolute' Cord Measurements at C.T. C2-3 Level: Control patients with no spinal lesion

\begin{tabular}{lcc}
\hline & Coronal & Sagittal \\
\hline G. G. & II.5 & $7 \cdot 5$ \\
J. L. & II.5 & $8 \cdot 5$ \\
A. G. & II.5 & $9 \cdot 5$ \\
G. L. & II.5 & $6 \cdot 5$ \\
M. McC. & II.0 & $7 \cdot 0$ \\
C. R. & II.0 & 6.5 \\
\hline
\end{tabular}

not permit meaningful statistical analysis and it is suggested that the ability of CT scan to display the cord in transverse section be emphasised rather than cord measurements until an adequate number of normal patients have been measured (Table VI).

It has been mentioned, however, that a proportion of patients with posttraumatic cystic myelopathy will be shown to have developed longitudinal or branching cavities within the spinal cord without actual cord enlargement. At present the only method of displaying these intramedullary defects is by injecting contrast material into the cavities at surgical exploration when the full extent of the spinal cord cavitation can be assessed with appropriate radiographs. We have no experience of this procedure at this Centre.

\section{TABLE VI}

Post-Traumatic Syringomyelia: Absolute cord measurements at C.T.

\begin{tabular}{llcc}
\hline & Level & Coronal & Sagittal \\
\hline B. L. & C5 & I2.5 & $7 \cdot 0$ \\
& C2-3 & I3.0 & 7.0 \\
& CI & II.0 & 7.5 \\
R. A. & C2-3 & I2.0 & 8.0 \\
& CI & II.0 & 7.5 \\
B. D. & C2-3 & I0.5 & 7.5 \\
& CI & I0.5 & 8.0 \\
\hline
\end{tabular}

Illustrative Case Reports

Case I. T. F. (D.o.B. 8.2.22). First presented in 1958 with T.B. meningitis, incomplete paraplegia, motor complete below Tio with some sensory preservation in lower limbs. Severe spasm for which alcohol was introduced intrathecally in I960 at T4-5 level with complete relief of spasm.

Presented in 1973 with a painless dislocation of right shoulder. Attempted repair of this grossly disorganised joint with poor result. Deceased I975. No post mortem permitted.

Case 2. L. B. (D.o.B. I904). Fracture-dislocation $\mathrm{L}_{3-4}$ level November 1964 as the result of a fall from a farm tractor. Normal sensation both lower limbs and 
upper limbs initially with an incomplete cauda equina lesion and able to ambulate with the aid of elbow crutches. In 1970 onset of loss of pain and temperature sensation in the right upper limb. In 1978 unstable dislocation of the right shoulder (Fig. 2). Attempted repair performed at a peripheral hospital. In I980 presented to the Spinal Unit with bilateral unstable shoulders and X-ray changes suggesting neuropathic joints. In view of age and general debility, further myelographic studies were not carried out, and referred to Regional Hospital for extended care and maintenance. Now confined to wheelchair as upper limb instability prevented ambulation with crutches.

Case 3. A. S. (D.o.B. 8.3.42). Fracture-dislocation at T8-9 level in I959 whilst in Germany serving with the British Armed Forces. Treated at the National Spinal Injuries Centre, Stoke Mandeville, and later migration to Australia. Severe spasm below the level of the lesion, for which alcohol block was carried out in I964. In September 1975 loss of sensation noted to pin-prick and temperature over the whole of the right upper limb, but without any pain in the right shoulder or the right elbow. In 1977 instability and swelling of the right elbow with X-ray changes commencing (Fig. 3). Proceeded to gross disorganisation of the right shoulder but without pain, and X-ray changes of a grossly neuropathic joint. Refused myelography.

Case 4. R. A. (D.o.B. 21.8.48). Fracture-dislocation T I I-I 2 level I97I, complete paraplegia below TI2 level. In November 1972 loss of pain and temperature
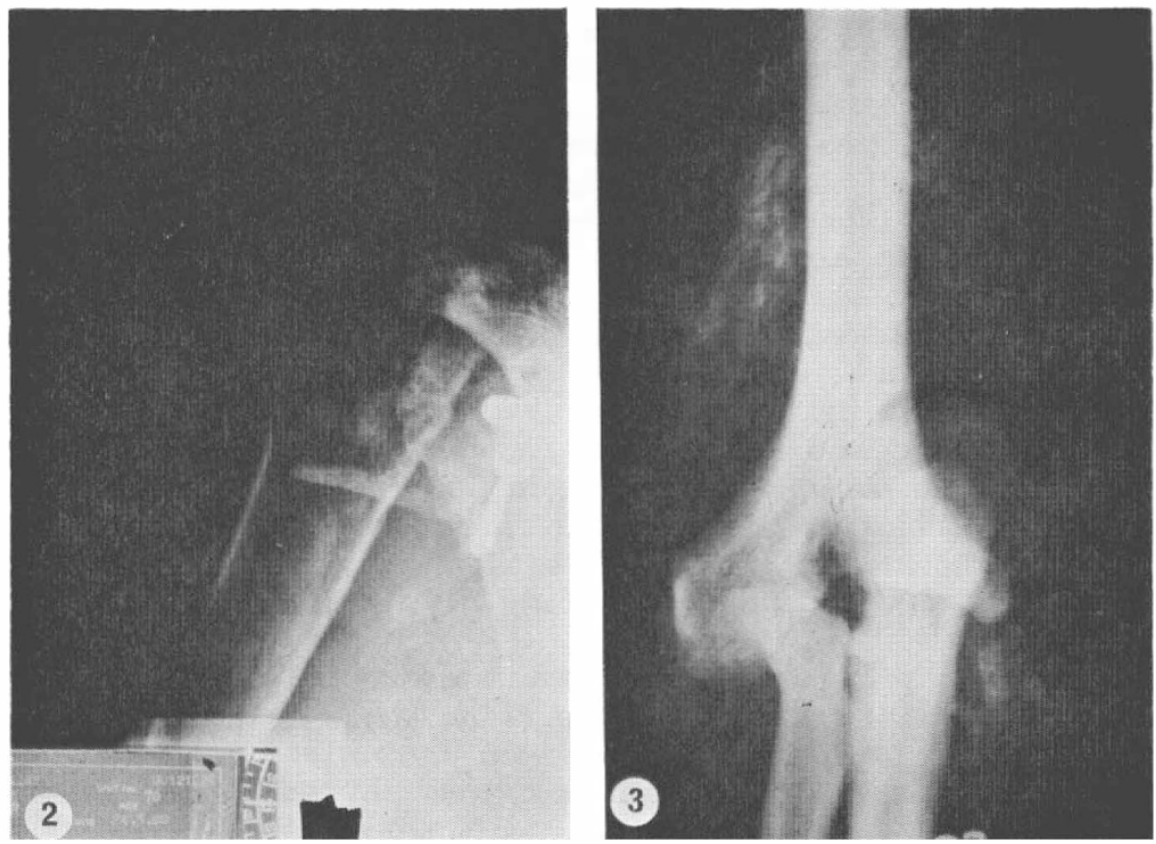

FIG. 2

Case 2. (L. B.) Shoulder joint showing neuropathic changes and attempted stabilisation.

FIG. 3

Case 3. (A. S.) Elbow disorganisation from neuropathic changes. 
sensation in the left upper limb in the sixth, seventh and eighth cervical dermatome distribution. No motor loss in the left upper limb. Myelography and CT scan performed with dilatation of the spinal cord displayed (Fig. 4).

Follow up since has revealed no further deterioration in sensory or motor function and he remains under observation.
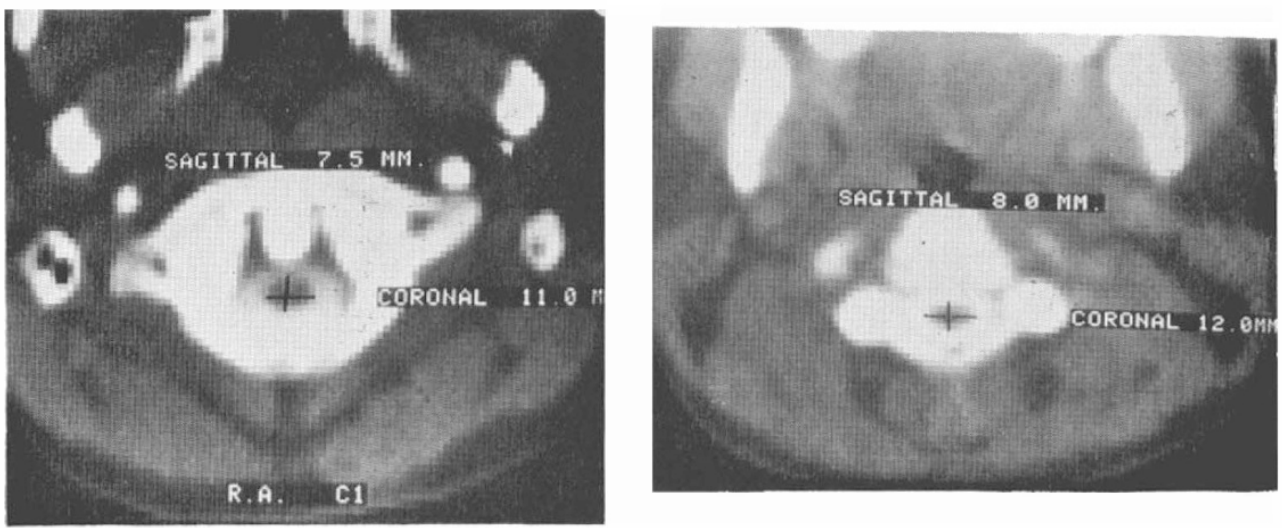

FIG. 4

Case 4. (R. A.) CT scan with metrizamide myelogram with sagittal and coronal dimensions of spinal cord (Normal Range < I I mm).

Case 5. B. L. (I8.10.37). Fracture-dislocation at TI2 upon Li level on 28.7.74. An Aboriginal rodeo rider who became incompletely paraplegic with ambulation with the aid of crutches and below-knee caliper on the left lower limb. Returned in August 1977, volunteering the information that sensation to cold was diminished in the right upper limb when driving his motor car with the right elbow resting out of the car window. Some difficulty in establishing diagnosis initially as he was thought to be a possible candidate for Hansen's Disease, because two of his children in the North-West of Western Australia did, indeed, have this disease. This was later clarified by histological examination of a sensory nerve in the hand, which proved to be negative.

Showing sensory and motor loss in the right upper limb from the fourth cervical dermatome downwards, myelogram carried out in September 1977 (Fig. 5) showing gross dilatation of the cervical cord from the second cervical segment downwards with a block at the level of dislocation of the twelfth thoracic upon the first lumbar vertebra. Further follow up has shown no increase in sensory loss, no motor loss or any disorganisation of peripheral joints. Still under observation.

Case 6. B. D. (D.o.B. I5.9.5I). Presented in September I970 as the result of a mining accident with a fracture-dislocation of the twelfth thoracic upon the first lumbar vertebra. Problems later ensued with psychiatric imbalance and drug dependency. In January 1979 metrizamide myelography and CT scan performed. No sensory or motor changes noted in this man's upper limbs.

We are at present investigating a potential seventh case who is an in-patient at the moment, presenting with very extensive decubitus ulcers over the ischial tuberosities I5 years after being a very well rehabilitated paraplegic and fully employed during this time in the same job. His explanation of the onset now of 

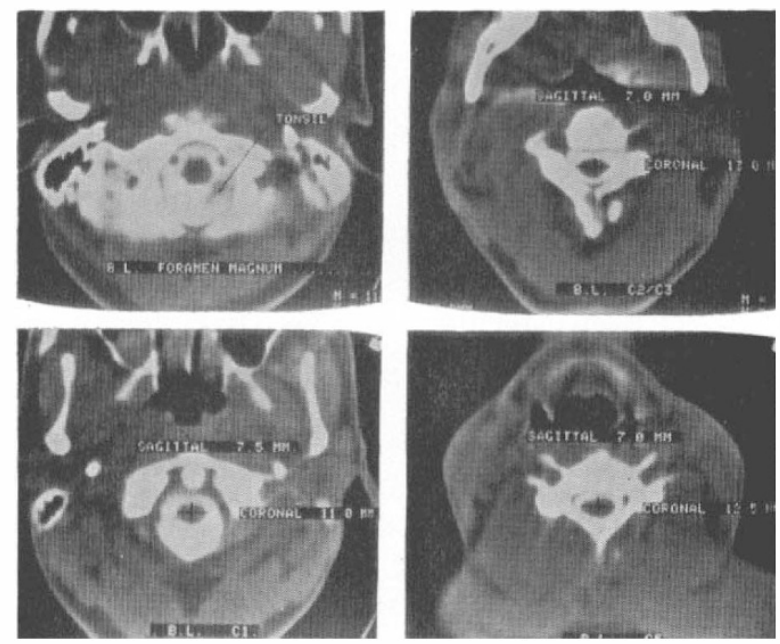

FIG. 5

Case 5. (B. L.) CT scan with metrizamide myelogram with sagittal and coronal dimensions of spinal cord (Normal Range < I I mm).

these pressure problems is that his upper limbs have become weak and he could no longer lift himself at frequent intervals in his wheelchair as before. Clinical assessment at this time shows loss of pain and temperature sensation in the right upper limb, and wasting of the intrinsic musculature in both hands. Further investigation will take place when the decubitus ulcers permit.

\section{Discussion}

The value of long-term follow up in apparently stable, well-rehabilitated paraplegic patients is demonstrated by the discovery of late neurological deficit in the upper limbs presenting in the follow-up period. In three of our cases, presentation was with an already established neuropathic joint, and in the remaining three they are at present static without further deterioration following the diagnosis of cystic degeneration being made. Surgical relief of the intramedullary cysts to prevent further deterioration has not yet been necessary in our Unit.

\section{SUMMARY}

The radiographic examinations performed in patients with post-traumatic syringomyelia are described.

At present, the most appropriate radiological demonstration of the pathology is obtained by metrizamide myelography followed by computerised tomography. We have performed this investigation in three of the six patients at this Centre who have developed the syndrome, and the abnormalities demonstrated in a typical case are presented.

\section{RÉSUMÉ}

Les examinations radiographiques qui ont été fait pour les malades avec la syringomyélie post-traumatique sont décrites.

Pour le moment, la démonstration radiologique de la pathologie la plus appropriée est 
obtenue par une myélographie de métrizamide, suivie par une tomographie computérisée. Nous avons fait cette recherche avec trois des six malades du Centre qui ont développé ce syndrome et les abnormalités d'un cas typique sont présentées.

\section{ZUSAMMENFASSUNG}

Die radiographischen Untersuchungen ausgeführt an Patienten mit nachneurotischer Syringomyelia sind hiermit beschrieben.

Gegenwärtig wird die meist geeignete Darstellung in der Pathologie durch Metrizamide Myelographie gefolgt von computerisierter Tomographie erreicht. Wir haben hier im Zentrum diese Untersuchungen bei drei von sechs Patienten, welche das Syndrome entwickelt hatten, durchgeführt. Die Abnormalitäten, die bei einem typischen Fall vorkommen, sind vorhanden.

\section{REFERENCES}

BARnetT, H. J. M. \& Jousse, A. T. (1976). Post-traumatic syringomyelia (cystic myelopathy). In: Injuries of the Spine and Spinal Cord. Part II. Handbook of Clinical Neurology, 26, pp. I I3-I57. North Holland Publishing Co., Amsterdam.

GARDNER (cited by BARNETT in above publication).

SCHER, A. T. (1976). Syringomyelia secondary to paraplegia due to fractures of the thoracic spine. S. Afr. Med.F., 50 (36), I406-1 408.

WATSON (1972). Personal communication, cited by BARnETt. 